\title{
Correction to: Incidence, risk factors and management of venous thromboembolism in patients with primary CNS lymphoma
}

\author{
Miyabi Saito ${ }^{1} \cdot$ Nolan A. Wages ${ }^{2}$ [D $\cdot$ David Schiff $^{3}$ D
}

Published online: 14 July 2021

(c) The Author(s), under exclusive licence to Springer Science+Business Media, LLC, part of Springer Nature 2021

\section{Correction to: Journal of Neuro-Oncology} https://doi.org/10.1007/s11060-021-03791-x

The initial online publication of this article contained the following minor errors:

- In the Abstract, the median time to VTE diagnosis should have been specified as 3 months (not 2 months).

- In the Abstract, hemoglobin level should have been specified in $\mathrm{g} / \mathrm{dL}$ (not $\mathrm{mg} / \mathrm{dL}$ ).

- In the Abstract and in the first paragraph of the Results, 'diabetes mellitus' should have read 'diabetes mellitus (type 1 or 2)’.
The original article has been corrected. These corrections have no impact on the results or conclusions of the study.

Publisher's Note Springer Nature remains neutral with regard to jurisdictional claims in published maps and institutional affiliations.

The original article can be found online at https://doi.org/10.1007/ s11060-021-03791-x.

David Schiff

davidschiff@ virginia.edu

1 UVA School of Medicine, University of Virginia, Charlottesville, VA 22903, USA

2 Division of Translational Research \& Applied Statistics, Department of Public Health Sciences, University of Virginia, P.O. Box 800717, Charlottesville, VA 22903-0717, USA

3 Divison of Neuro-Oncology, Department of Neurology, University of Virginia, PO Box 800432, Charlottesville, VA 22908-0432, USA 